\title{
Reference applications for renewable heat
}

Compilation of reference applications for integrated energy systems with solar heating plants incl. representative load profiles

IEA SHC TASK 64 | IEA SolarPACES Task 4 | Solar Process Heat 


\section{Reference applications for renewable heat}

\section{This is a report from SHC Task 64 / SolarPACES Task IV: Solar Process Heat and work performed in Subtask A: Integrated Energy Systems}

F. Pag, M. Jesper, U. Jordan (University of Kassel) with contributions from W. Gruber-Glatzl, J. Fluch (AEE INTEC) 25.01.2021

Deliverable Report D.A1, doi:10.17170/kobra-202104263730

The contents of this report do not necessarily reflect the viewpoints or policies of the International Energy Agency (IEA) or its member countries, the IEA Solar Heating and Cooling Technology Collaboration Programme (SHC TCP) members or the participating researchers. 


\section{Solar Heating and Cooling Technology Collaboration Programme (IEA SHC)}

The Solar Heating and Cooling Technology Collaboration Programme was founded in 1977 as one of the first multilateral technology initiatives ("Implementing Agreements") of the International Energy Agency.

Our mission is "Through multi-disciplinary international collaborative research and knowledge exchange, as well as market and policy recommendations, the IEA SHC will work to increase the deployment rate of solar heating and cooling systems by breaking down the technical and non-technical barriers."

IEA SHC members carry out cooperative research, development, demonstrations, and exchanges of information through Tasks (projects) on solar heating and cooling components and systems and their application to advance the deployment and research and development activities in the field of solar heating and cooling.

Our focus areas, with the associated Tasks in parenthesis, include:

- $\quad$ Solar Space Heating and Water Heating (Tasks 14, 19, 26, 44, 54)

- Solar Cooling (Tasks 25, 38, 48, 53, 65)

- Solar Heat for Industrial and Agricultural Processes (Tasks 29, 33, 49, 62, 64)

- Solar District Heating (Tasks 7, 45, 55)

- Solar Buildings/Architecture/Urban Planning (Tasks 8, 11, 12, 13, 20, 22, 23, 28, 37, 40, 41, 47, 51, 52, $56,59,63,66)$

- $\quad$ Solar Thermal \& PV (Tasks $16,35,60)$

- Daylighting/Lighting (Tasks 21, 31, 50, 61)

- Materials/Components for Solar Heating and Cooling (Tasks 2, 3, 6, 10, 18, 27, 39)

- $\quad$ Standards, Certification, and Test Methods (Tasks 14, 24, 34, 43, 57)

- $\quad$ Resource Assessment (Tasks 1, 4, 5, 9, 17, 36, 46)

- $\quad$ Storage of Solar Heat (Tasks 7, 32, 42, 58)

In addition to our Task work, other activities of the IEA SHC include our:

$>$ SHC Solar Academy

$>$ Solar Heat Worldwide, annual statics report

$>$ SHC International Conference

\section{Our members}

$\begin{array}{lll}\text { Australia } & \text { European Copper Institute } & \text { SACREEE } \\ \text { Austria } & \text { France } & \text { Slovakia } \\ \text { Belgium } & \text { Germany } & \text { South Africa } \\ \text { Canada } & \text { International Solar Energy } & \text { Spain } \\ \text { CCREEE } & \text { Society } & \text { Sweden } \\ \text { China } & \text { Italy } & \text { Switzerland } \\ \text { Denmark } & \text { Netherlands } & \text { Turkey } \\ \text { EACREEE } & \text { Norway } & \text { United Kingdom } \\ \text { ECREEE } & \text { Portugal } & \\ \text { European Commission } & \text { RCREEE } & \end{array}$

For more information on the IEA SHC work, including many free publications, please visit www.iea-shc.org 


\section{Solar Power and Chemical Energy Systems Technology Collaboration Programme (IEA SolarPACES)}

The SolarPACES Technology Collaboration Programme was founded in 1977 as one of the first multilateral technology initiatives ("Implementing Agreements") of the International Energy Agency.

Our mission is to facilitate technology development, market deployment and energy partnerships for sustainable, reliable, efficient and cost-competitive concentrating solar power technologies by providing leadership as the international network of independent experts.

To realize this mission, SolarPACES coordinates and advances concentrating solar technology research, by focusing on the next generation of technologies, by providing information and recommendations to policy makers and by organizing international conferences, workshops, reports and task meetings.

Our focus areas are organized in six tasks:

- Task I: Solar Thermal Electric Systems

- Task II: Solar Chemistry Research

- Task III: Solar Technology and Advanced Applications

- Task IV: Solar Heat Integration in Industrial Processes

- Task V: Solar Resource for High Penetration and Large Scale Applications

- Task VI: Solar Energy and Water Processes and Applications

In addition to our Task work, other activities of the IEA SolarPACES include:

$>$ SolarPACES International Conference.

$>$ Review of CSP market and cost data with the International Renewable Energy Agency (IRENA).

$>$ Joint project on solar resource for high penetration and large scale applications in collaboration with the TCP on Photovoltaic Power Systems (PVPS TCP).

$>$ Project in solar process heat in collaboration with the TCP on Solar Heating and Cooling (SHC TCP).

\section{Our members}

$\begin{array}{lll}\text { Australia } & \text { Austria } & \text { Brazil } \\ \text { Chile } & \text { China } & \text { European Commission } \\ \text { France } & \text { Germany } & \text { Greece } \\ \text { Israel } & \text { Italy } & \text { Mexico } \\ \text { Morocco } & \text { Namibia } & \text { Republic of Korea } \\ \text { South Africa } & \text { Spain } & \text { Switzerland } \\ \text { United Arab Emirates } & \text { United States of America } & \end{array}$

For more information on the IEA SolarPACES work, including many free publications, please visit: 


\section{Contents}

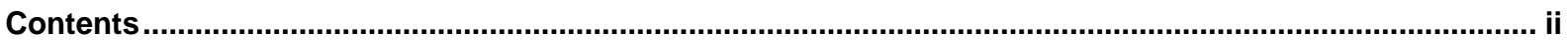

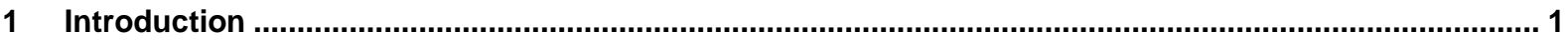

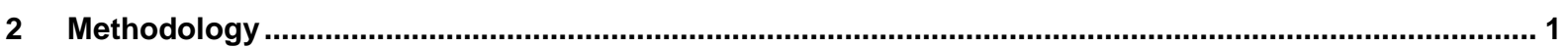

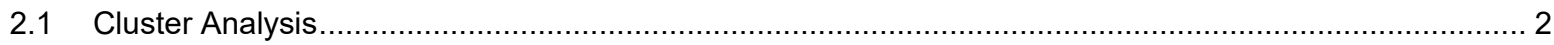

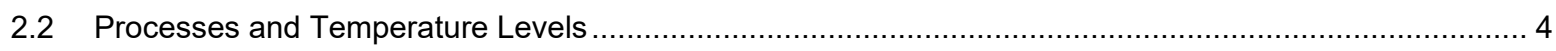

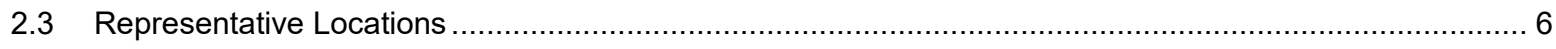

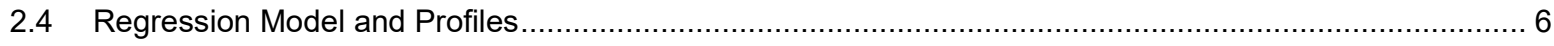

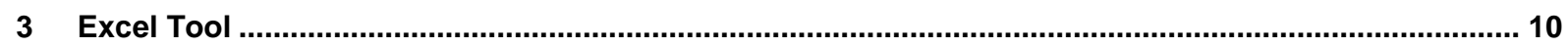

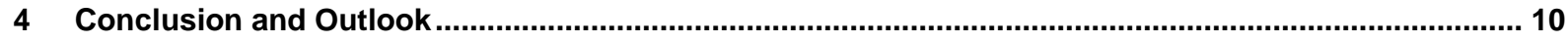

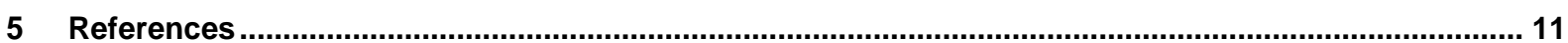




\section{Introduction}

There is a high degree of freedom and flexibility in the way to integrate renewable process heat in industrial processes. Nearly in every industrial or commercial application various heat sinks can be found, which are suitable to be supplied by renewable heat, e.g. from solar thermal, heat pumps, biomass or others. But in contrast to conventional fossil fuel powered heating systems, most renewable heating technologies are more sensitive to the requirements defined by the specific demand of the industrial company. Fossil fuel-based systems benefit from their indifference to process temperatures in terms of energy efficiency, their flexibility with respect to partload as well as on-off operation, and the fuel as a (unlimited) chemical storage. In contrast, the required temperature and the temporal course of the heat demand over the year determine whether a certain regenerative heat generator is technically feasible at all or at least significantly influence parameters like efficiency or coverage rate. Additionally, feasibility and performance of renewable heating systems are also significantly influenced by the availability of heat sources (solar irradiation, ambient heat etc.) which also varies in time. To be able to compare the potential of the coverage and the performance of renewable heating systems globally, first, it is necessary to attain a profound overview of the variety of reference conditions for renewable heating systems. The following reference conditions of industrial processes are decisive:

- $\quad$ Temporal course of heat demand (load profile):

While there are several methods available to estimate the expected load profiles of residential buildings, little is known about the load profiles in the industrial and commercial sectors, especially when there is a high share of industrial process heat to the overall heat demand. To fill this knowledge gap, industrial gas consumption profiles are collected. In some cases, natural gas might be used as material but in most cases, it is burned and transformed to heat in gas boilers. Therefore, the gas consumption is assumed to be equal to the heat demand. In total, 797 natural gas consumption profiles with an hourly resolution from industrial and large commercial, residential and public consumers $(>1.5 \mathrm{GWh} / \mathrm{a})$ are collected, all from German consumers. Using this database, the activities in Subtask $A$ are focused on the development of a methodology to categorize and develop standard heat demand profiles.

- Temperature requirements determined by heat sinks:

Suitable temperature levels are selected according to studies on temperature requirements of a broad range of heat sinks available in the literature.

- Availability of renewable heat sources:

As heat sink and source characteristics are also dependent on the location, a method to characterize the seasonality of the temperatures and heat loads at different locations is developed. Based on this methodology, representative locations are selected.

Within this work, process heat demand is defined as the overall heat demand of an industrial company, which is composed of traditional process heat demand, e.g. heating up baths or streams of diverse fluids, and space heating. Usually, the entire heat demand is covered by one system and one heating network. Thus, aiming at the most complete decarbonization possible, it is not purposeful to make a distinction between these applications as a $100 \%$ renewable heating system must provide heat for both.

This deliverable aims to create an overview on the requirements to renewable heating systems by defining reference applications composed of a load profile, a temperature level and a location. Each of these reference applications is supposed to be representative for a broad range of different industry sectors and locations. All defined reference applications combined are intended to represent the entire range of worldwide possible variability of heat sinks.

\section{Methodology}

In this section, the methodology to define reference applications is outlined. The methodology for load profile categorization is summarized in section 2.1. Section 2.2 describes which temperature levels are selected. The methodology to select reference locations is recapped in section 2.3. Finally, section 2.4 summarizes how load profiles are created based on an ambient temperature profile. 


\subsection{Cluster Analysis}

One very important variable influencing heat load profiles is stated to be the daily mean ambient temperature of the respective location [1]. Space heating demand and the heat demand of many processes, e.g. drying with heated ambient air, depends on the ambient temperature. Consequently, many of the more than 797 gathered load profiles show a strong seasonality. This is because the profiles are from a temperate climate in Germany. In this climate, the yearly amplitude between maximum and minimum of mean daily ambient temperatures is relatively high $(\approx 40 \mathrm{~K})$. In contrast to that, the mean daily ambient temperature is far more constant in subtropical or tropical climates. Therefore, the share of load profile variance that can be explained by ambient temperature dependency is significantly smaller in sub-tropical or tropical climates. Other parameters to explain the rest of the load profile variance are, for example, degree of capacity utilization and type and operation of heat generators which can be summed up under user behaviour. As no further information about the companies behind the profiles, their products, utilities, etc. is known, the influences that can be traced back to this cannot be analyzed. Nevertheless, for most of the gathered profiles, ambient temperature is suitable to explain the greatest part of the overall load profile variance, especially when the daily heat demand is considered separately for working days and weekends or holidays. Additionally, user behaviour cannot be predicted without detailed information on a specific consumer which is not available in many cases. Therefore, ambient temperature is the only parameter used for load profile categorization and the development of standard profiles in this study.

The absolute gas consumption of the examined consumers varies strongly, even within the single industry sectors. However, to achieve the goal of this analysis, the absolute values of gas consumption are of little importance because they only represent a scaling factor. To focus on relative differences, load profiles are normalized to the mean gas consumption on working days with an average ambient temperature of $8{ }^{\circ} \mathrm{C}$.

To categorize the heat demand of the examined consumers, the load profiles are clustered by their dependency on ambient temperature using a machine learning algorithm (K-Means). With four working day (wd) clusters (Figure 1), the analysis shows a good compromise between accuracy and a manageable small number of clusters. From wd-clusters 0 to 3 , the dependency on ambient temperature continuously increases. For consumers in wd-cluster 0 , gas consumption is roughly the same on each working day of the year. In the case of the ambient temperature dependent clusters, the summer load decreases from wd-clusters 1 to 3.
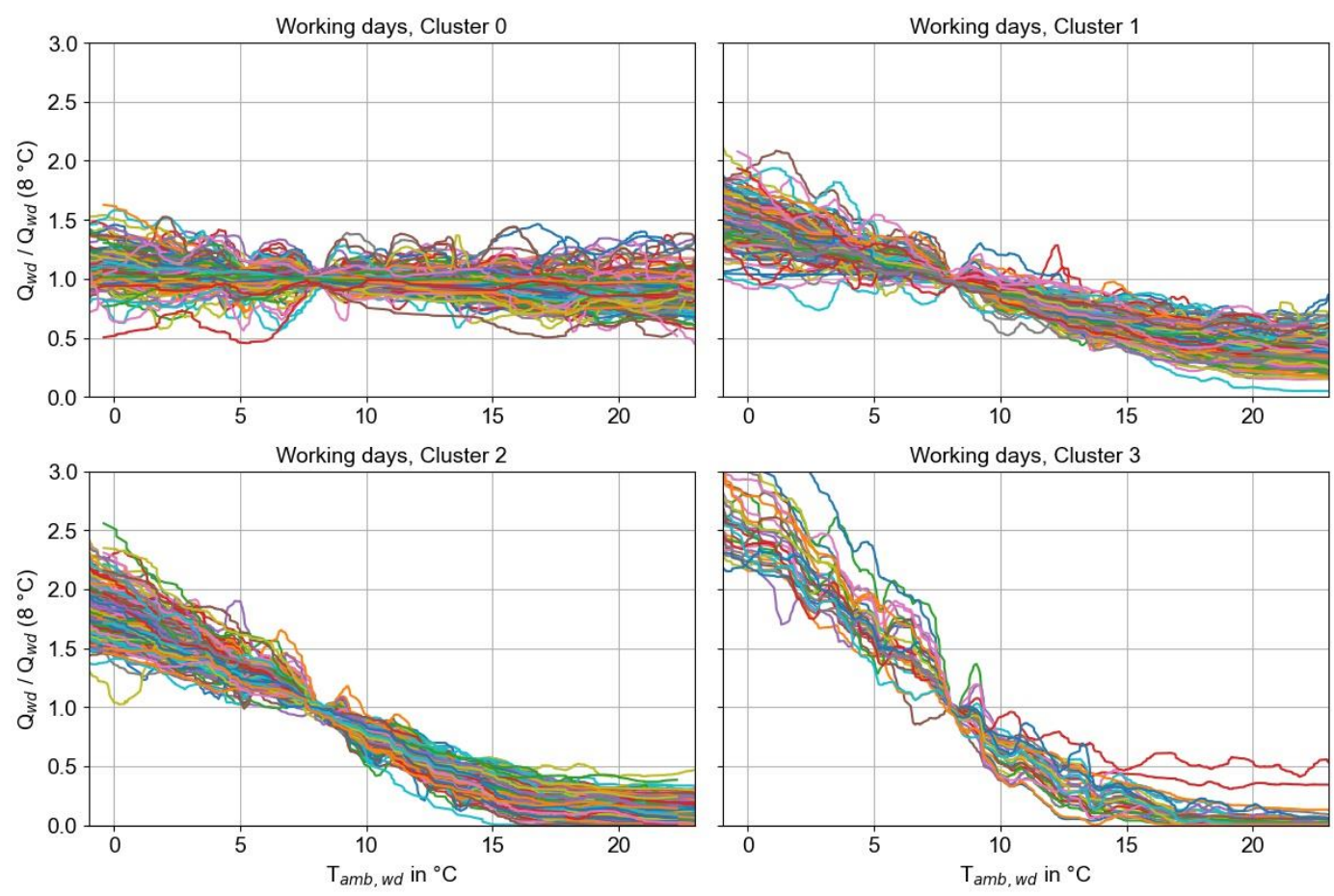

Figure 1: Results of k-Means clustering for working day gas consumption (to keep the figure clean of outliers, the triangular weighted moving average ( \pm 15 periods) of each load profile is illustrated). 
For many load profiles from commercial consumers, there is a clear difference between gas consumption on working days (wd) and weekends or holidays (wknd). Therefore, the cluster analysis is done separately for wd and wknds (Figure 2). An additional cluster (cluster 1) is necessary to consider those consumers with a significantly reduced load on wknd. The other four wknd clusters show a similar trend but just a slightly lower gas consumption compared to their wd pendants.
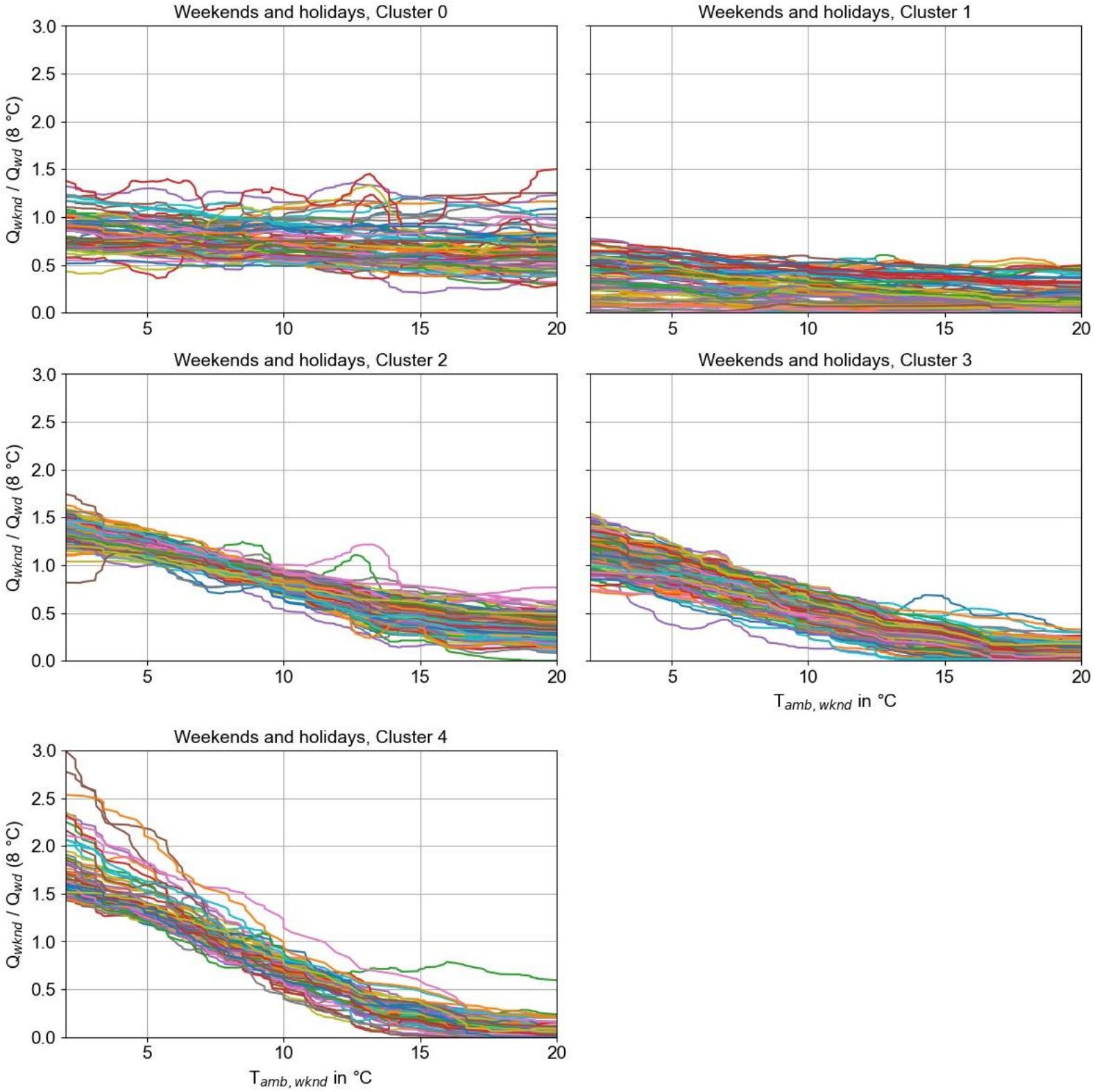

Figure 2: Results of k-Means clustering for weekend and holiday gas consumption (to keep the figure clean of outliers, the triangular weighted moving average ( \pm 15 periods) of each load profile is illustrated).

The shares of the different clusters found in each industry sector (Figure 3 and Figure 4) reveal that some subsectors like the production of food products or beverages are dominated by a process heat demand that is not dependent on the ambient temperature. For some other subsectors like the manufacturing of computer, electronic and optical products or the manufacturing of electrical equipment, almost all consumers show a dependency on the ambient temperature. 


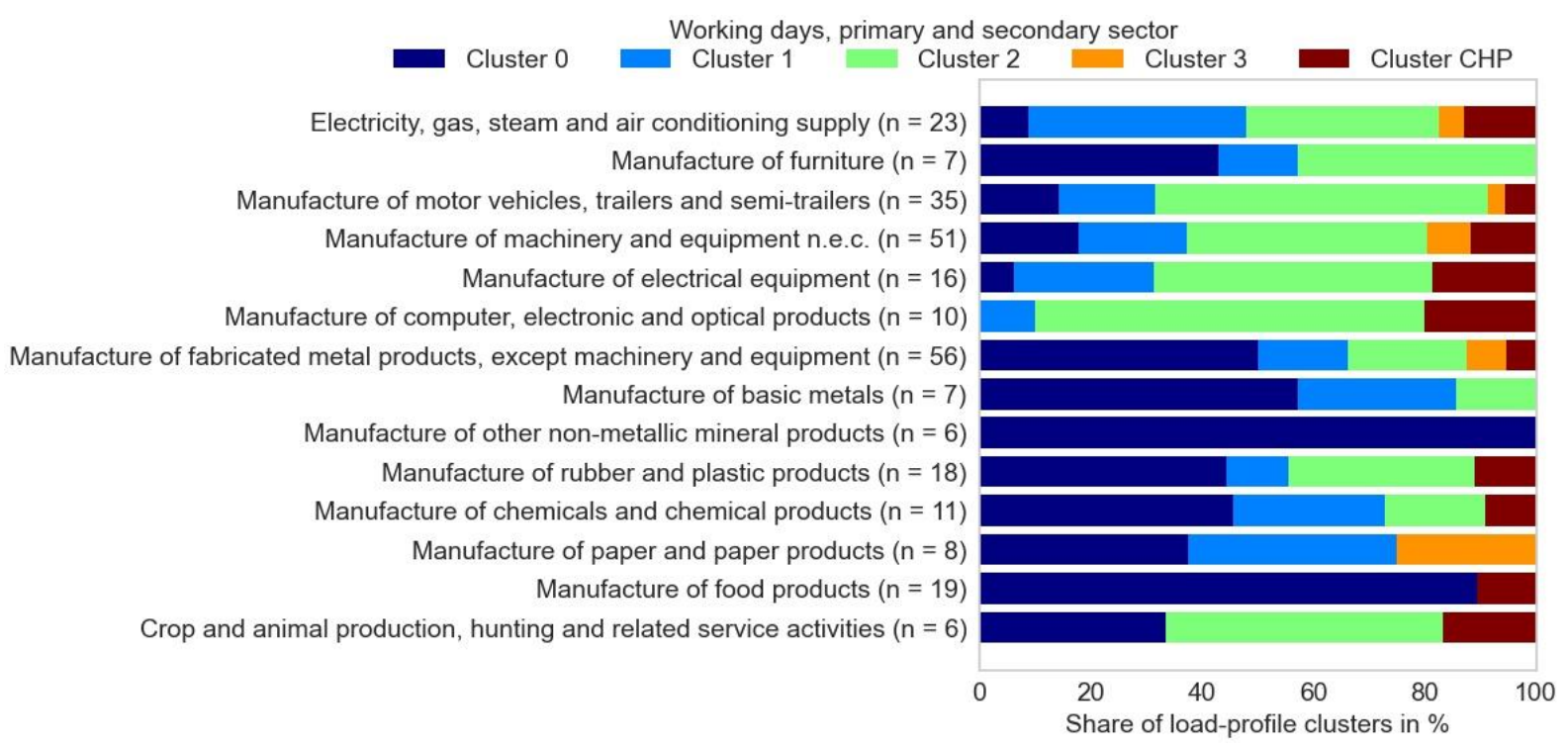

Figure 3: Shares of wd-Clusters in primary and secondary sectors (just economy divisions with at least 5 load profiles).

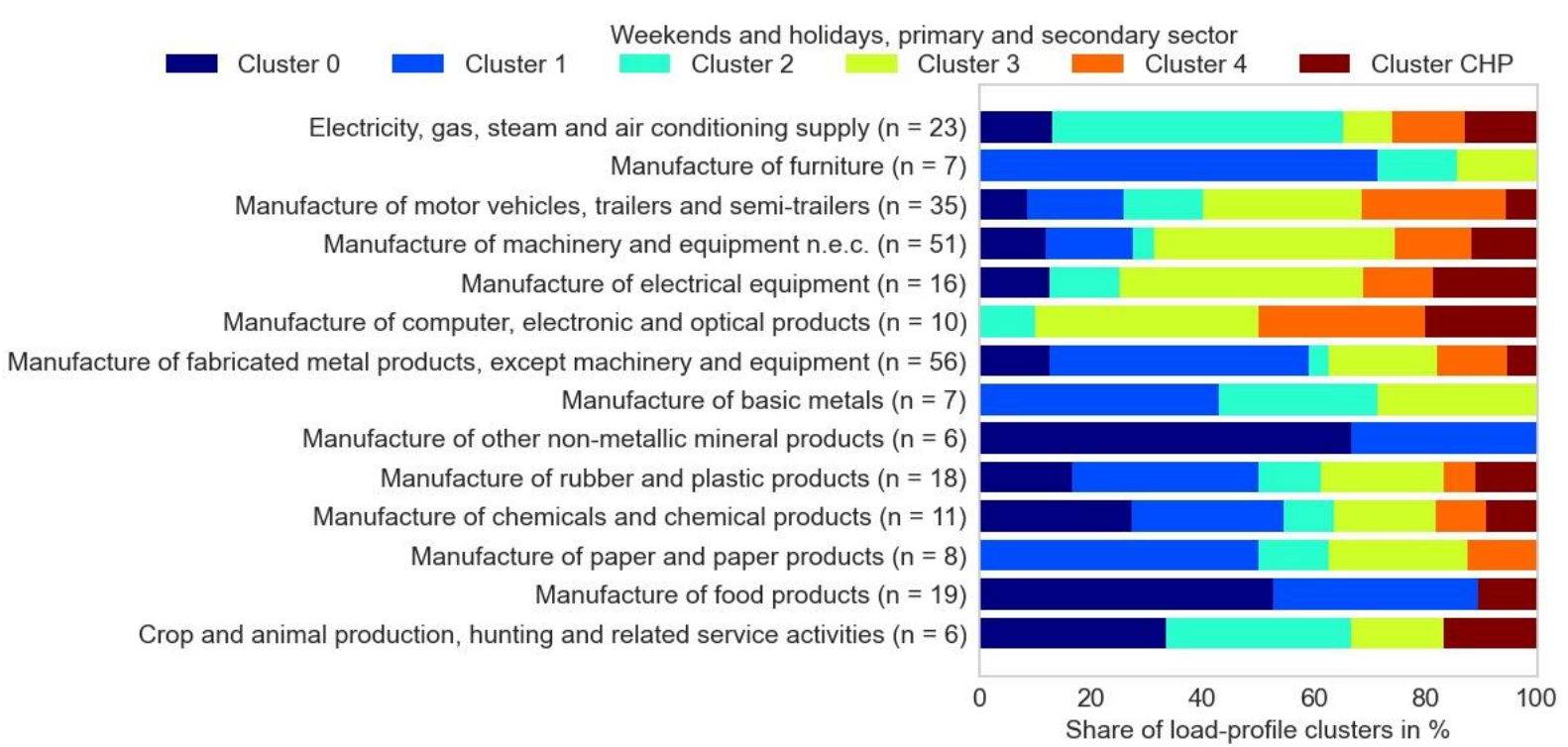

Figure 4: Shares of wknd-Clusters in primary and secondary sectors (just economy divisions with at least 5 load profiles).

\subsection{Processes and Temperature Levels}

Renewable heat generators like solar thermal or heat pumps are sensible to heat sink and source temperatures. For example, the efficiency of solar thermal collectors decreases if the difference between heat carrier and ambient temperatures is increased or heat pump efficiency decreases if the temperature difference between heat source and sink temperatures is increased. Consequently, heat sink and source temperatures are a major influence on economic feasibility of renewable heating systems.

Schmitt [2] found that, in a temperate climate, economic feasibility of solar process heat plants is often limited to heat sink temperatures of up to $100^{\circ} \mathrm{C}$. At the same time, the majority of commercially available large-scale heat pumps is limited to heat sink temperatures of $100{ }^{\circ} \mathrm{C}$ [3]. Figure 6 illustrates temperature levels of common production processes in the temperature range up to $240{ }^{\circ} \mathrm{C}$. An accumulation of processes at temperatures around $80^{\circ} \mathrm{C}$ is discernible. For these reasons, $80^{\circ} \mathrm{C}$ is selected as a reference heat sink temperature to be investigated in this Task. 
Besides economic feasibility, technical feasibility is another important parameter limiting the application of renewable heating systems. For example, commercially available large-scale heat pumps are limited to heat sink temperatures of up to $160^{\circ} \mathrm{C}$ [3]. Heat sink temperatures of around $150{ }^{\circ} \mathrm{C}$ are also limiting the application of most non-concentrating solar thermal collectors [2]. Hence, $150{ }^{\circ} \mathrm{C}$ is selected as a second heat sink temperature to be investigated in this Task.

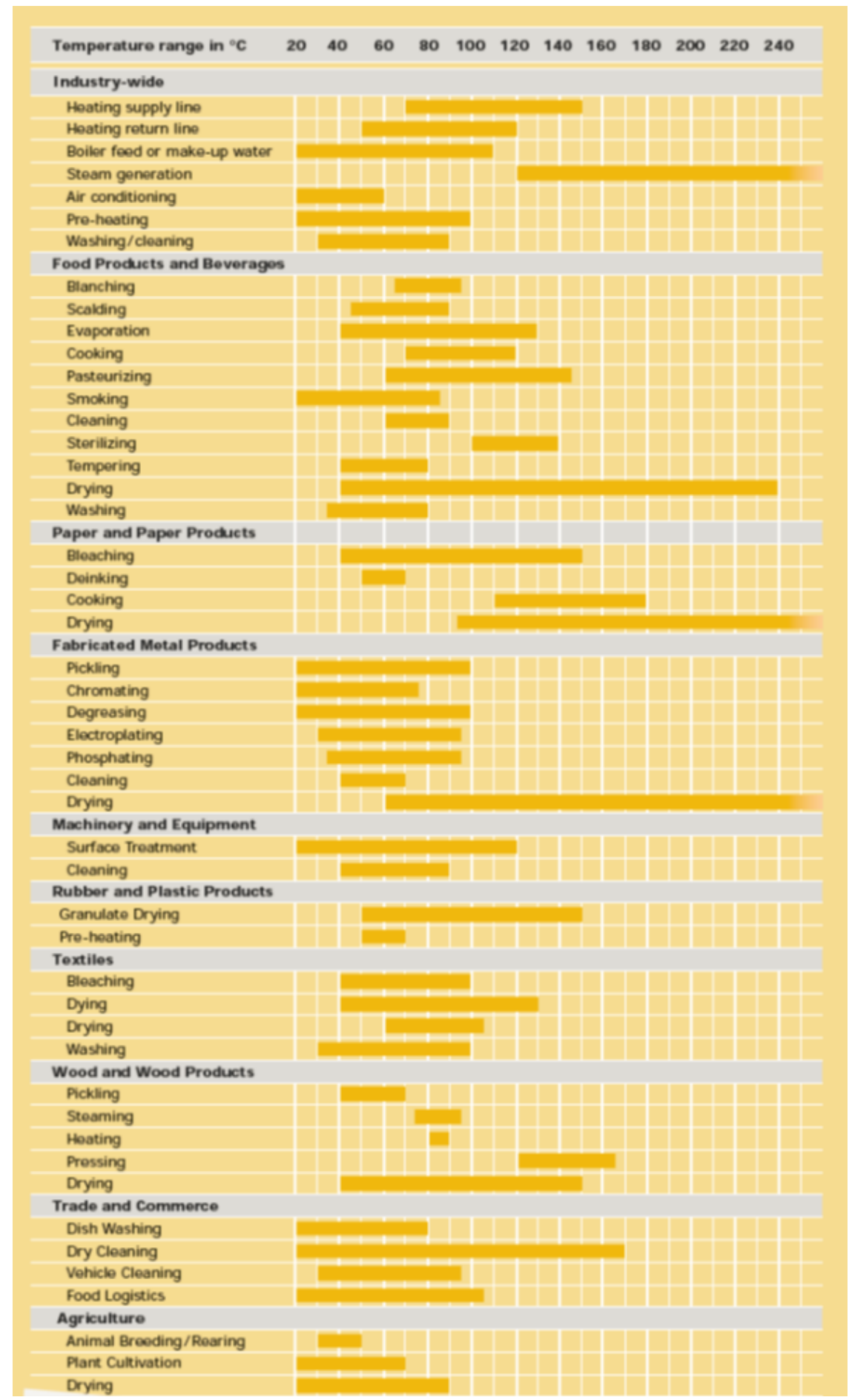

Figure 5 Overview of typical sector specific processes in Industry and Commerce with their respective temperature level [2] 


\subsection{Representative Locations}

As described above, special attention has to be paid to seasonally changing parameters when renewable heating systems are examined. Figure 6 visualizes the seasonal variability of two of the most important weather parameters for renewable heating systems for various locations in climate zones 3,4 and 5 (temperate, subtropical and tropical):

- The amplitude of monthly mean ambient temperature strongly influences the shape of heat demand load profiles. The higher the amplitude is, the more pronounced is the seasonality of consumption with a high share of space heating or ambient temperature depending process heat demand. Additionally, the availability of ambient heat as a heat source for heat pumps is also reflected by the amplitude of ambient air temperature. The higher the amplitude is, the higher is the probability to have periods where ambient heat is only conditionally or not usable at all, for example to prevent freezing or by other technical limitations (e.g. maximum difference between heat source and sink temperature).

- For many consumers, heat demand is concentrated in winter. In contrast, irradiation is concentrated in summer. The ratio of maximum to minimum global horizontal irradiation, $\Delta \mathrm{H}_{\mathrm{GH}}$, is a metric for the seasonality of solar irradiation. The higher this seasonality is, the less likely is a high temporal overlap of heat demand and solar irradiation.

In simplified terms, it can be summarized that from the upper left to the lower right of Figure 6 , the anticipated complexity of a solar heating system (storage size etc.), which is required for a high proportion of solar heat supply, decreases. In the case of locations in the lower right corner, solar heating systems can potentially supply $100 \%$ of heat demand with, for example, just a one-day storage capacity. For heat pumps utilizing ambient heat, the same can be applied but just in a vertical direction.

By trend, climate zones are also lining up from the upper left to the lower right. To choose a location which represents a kind of average in terms of the discussed parameters influencing renewable heating systems, one location from the center of each climate zone is selected (Bern, Casablanca and Bangkok).

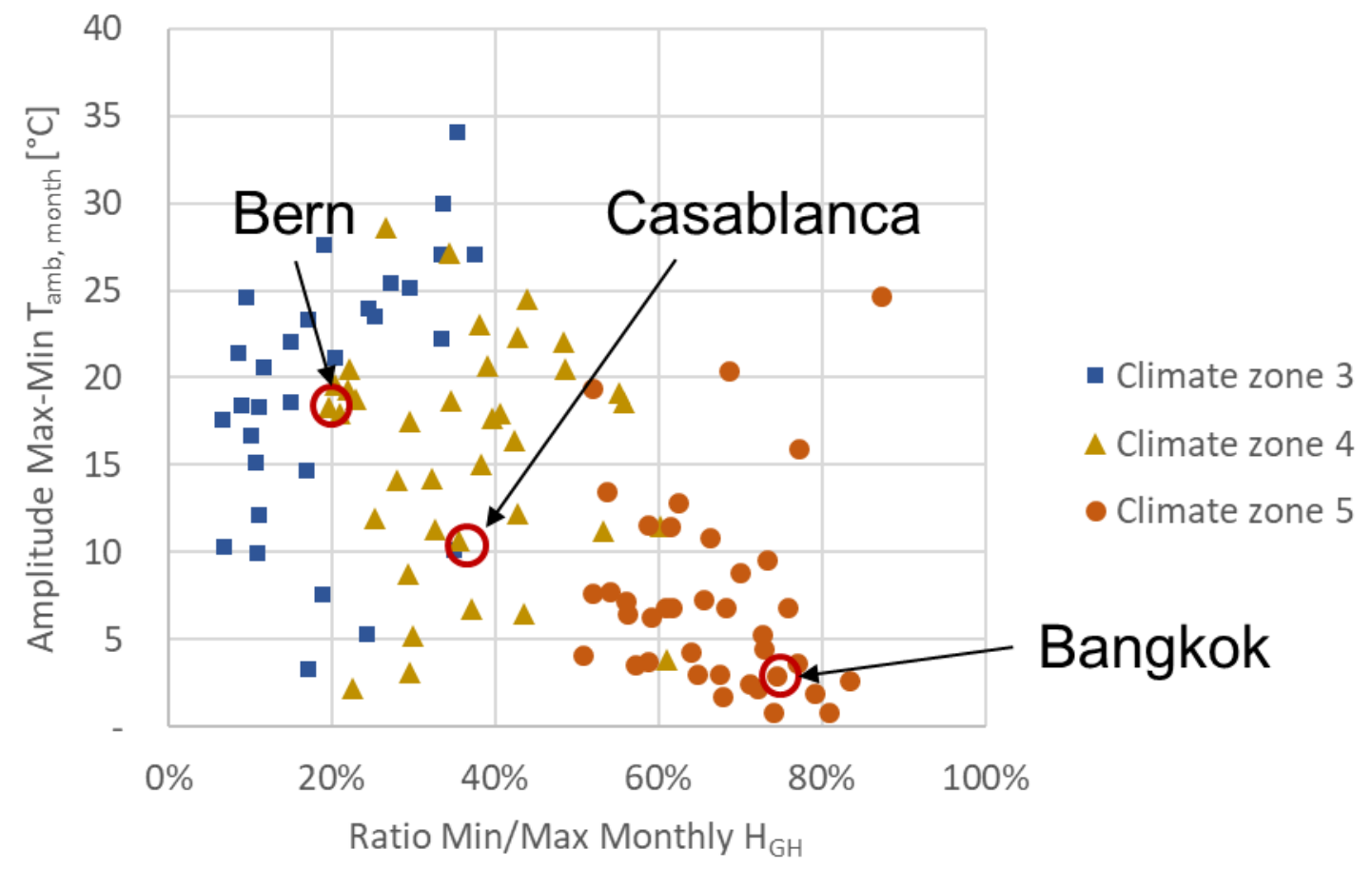

Figure 6: Definition of three reference Locations by analyzing the seasonality of ambient temperature and global horizontal irradiance

\subsection{Regression Model and Profiles}

In order to derive generic load profiles that can be mathematically described, the correlation between ambient temperature and heat demand for each individual customer and for a group of customers as defined in the clusters from section 2.1 are evaluated by a regression analysis. Two lines are fitted separately for working days 
and weekends or holidays to each of the consumers individually and to all consumers assigned to one of the found clusters (Figure 7 ). In the case of individually fitted functions, the mean coefficient of determination $\left(R^{2}\right)$ for estimated load profiles is 0.79 and the standard deviation $(\sigma)$ of residuals between original load profiles and the fitted functions is 0.21 . In the case of the cluster regressions, $R^{2}(0.71)$ and $\sigma(0.24)$ are just slightly poorer.

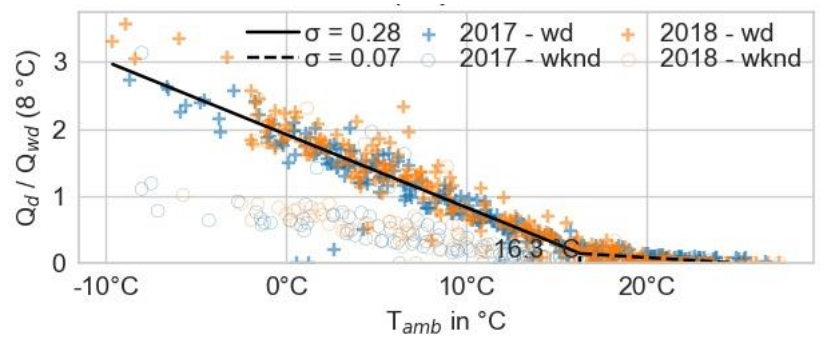

Figure 7: Two lines fitted to gas consumption of working days of an exemplary consumer.

To create normalized cluster load profiles for each of the selected representative locations, Eq. 1 and the respective parameters listed in Table 1 are used. To create an absolute load profile based on normalized load profiles, Eq. 2 and additional information about the seasonal sum of heat demand is required. Since absolute heat demand is just a scaling factor and to ensure comparability, an annual heat demand of $1 \mathrm{GWh} / \mathrm{a}$ is specified for all applications in this study. To easily apply the described methodology for reference load profile generation, an Excel tool was created (section 3).

$b_{h} \quad \mathrm{y}$-axis intercept of heating line [-]

$$
\begin{gathered}
h\left(T_{a m b}\right)=\frac{Q_{d}}{Q_{d}\left(8^{\circ} \mathrm{C}\right)}=\left\{\begin{array}{l}
m_{h} \cdot T_{a m b}+b_{h} \text { if } T_{a m b}<T_{h l} \\
m_{w} \cdot T_{a m b}+b_{w} \text { if } T_{a m b} \geq T_{h l}
\end{array}\right. \\
Q_{d}\left(8^{\circ} \mathrm{C}\right)=\frac{Q_{s}}{\sum_{i=1}^{j} h\left(T_{a m b}\right)_{i}}
\end{gathered}
$$

$b_{w} \quad \mathrm{y}$-axis intercept of domestic hot water line [-]

$h\left(T_{a m b}\right) \quad$ normalized daily gas consumption as sig or siglin function of $T_{a m b}[-]$

$j \quad$ number of days in examined season [-]

$m_{h} \quad$ slope of heating line [-]

$m_{w} \quad$ slope of water line [-]

$Q_{d} \quad$ daily gas consumption [kWh]

$Q_{d}\left(8^{\circ} \mathrm{C}\right) \quad$ gas consumption on days with $8{ }^{\circ} \mathrm{C}$ ambient temperature [kWh]

$Q_{s} \quad$ seasonal (usually annual) gas consumption (minimum 300 days) [kWh]

$T_{a m b} \quad$ ambient temperature [ $\left.{ }^{\circ} \mathrm{C}\right]$

$T_{h l} \quad$ heating limit temperature $\left[{ }^{\circ} \mathrm{C}\right]$

\begin{tabular}{|c|c|c|c|c|c|c|}
\hline & Cluster & $\mathbf{b}_{h}$ & $\mathbf{m}_{\mathbf{h}}$ & $\mathbf{b}_{\mathbf{w}}$ & $\mathbf{m}_{\mathbf{w}}$ & $\mathbf{T}_{\mathrm{hl}}$ \\
\hline \multirow[b]{4}{*}{ wd } & 0 & 1,0852 & $-0,0154$ & 1,0610 & $-0,0071$ & $2,9^{\circ} \mathrm{C}$ \\
\hline & 1 & 1,4695 & $-0,0588$ & 0,6779 & $-0,0133$ & $17,4^{\circ} \mathrm{C}$ \\
\hline & 2 & 1,7719 & $-0,0960$ & 0,4070 & $-0,0128$ & $16,4^{\circ} \mathrm{C}$ \\
\hline & 3 & 2,5404 & $-0,1780$ & 0,5210 & $-0,0215$ & $12,9^{\circ} \mathrm{C}$ \\
\hline \multirow[b]{4}{*}{ wknd } & $\mathbf{0}$ & 0,8814 & $-0,0124$ & 0,6661 & $-0,0003$ & $17,9^{\circ} \mathrm{C}$ \\
\hline & 1 & 0,4053 & $-0,0132$ & 0,1961 & $-0,0006$ & $16,6^{\circ} \mathrm{C}$ \\
\hline & 2 & 1,4792 & $-0,0661$ & 0,6527 & $-0,0160$ & $16,5^{\circ} \mathrm{C}$ \\
\hline & 3 & 1,3112 & $-0,0753$ & 0,2952 & $-0,0098$ & $15,5^{\circ} \mathrm{C}$ \\
\hline
\end{tabular}

Table 1: Cluster regression parameters 


\begin{tabular}{|l|l|l|l|l|l|l|}
\hline & $\mathbf{4}$ & 1,9425 & $-0,1201$ & 0,4449 & $-0,0175$ & $14,6^{\circ} \mathrm{C}$ \\
\hline
\end{tabular}

For each location, 20 different load profiles can be created with different combinations of wd and wknd cluster regressions but just 14 occur amongst the examined consumers (Figure 8). Nevertheless, 14 different load profiles at three defined locations and two different temperature levels result in 84 (14 profiles $\times 3$ locations $\times 2$ temperature levels) reference applications, which is not manageable. To further reduce the number of reference applications, just the following high frequent combinations of wd and wknd clusters are selected:

- Wd-cluster: 0; wknd-cluster: 0 (Bern, Casablanca \& Bangkok; heat sink temperatures $80{ }^{\circ} \mathrm{C}$ and $150{ }^{\circ} \mathrm{C}$ )

- Wd-cluster: 1; wknd-cluster: 2 (Bern, Casablanca \& Bangkok; heat sink temperatures $80^{\circ} \mathrm{C}$ and $150{ }^{\circ} \mathrm{C}$ )

- Wd-cluster: 2: wknd-cluster: 3 (just Bern; heat sink temperatures $80^{\circ} \mathrm{C}$ and $150{ }^{\circ} \mathrm{C}$ )

Since the latter is hypothetically caused by a high share of space heating on overall heat demand, this combination is not reasonable to be applied for Bangkok and Casablanca where the temperature profile is quite balanced throughout the year. Therefore, Wd-cluster 1 in Bangkok already shows only slight differences to Wdcluster 0 . To show this effect and for the sake for completeness, Wd-cluster 1 is still shown for Bangkok. Wdcluster 3 only occurs 32 times in total, representing less than $6 \%$ of the profiles (Figure 8 ), and is therefore not included to the further analysis. Each of the selected cluster combinations represents various industry sectors with a high likelihood (Figure 3 and Figure 4). Therefore, reference applications are not defined in more detail.

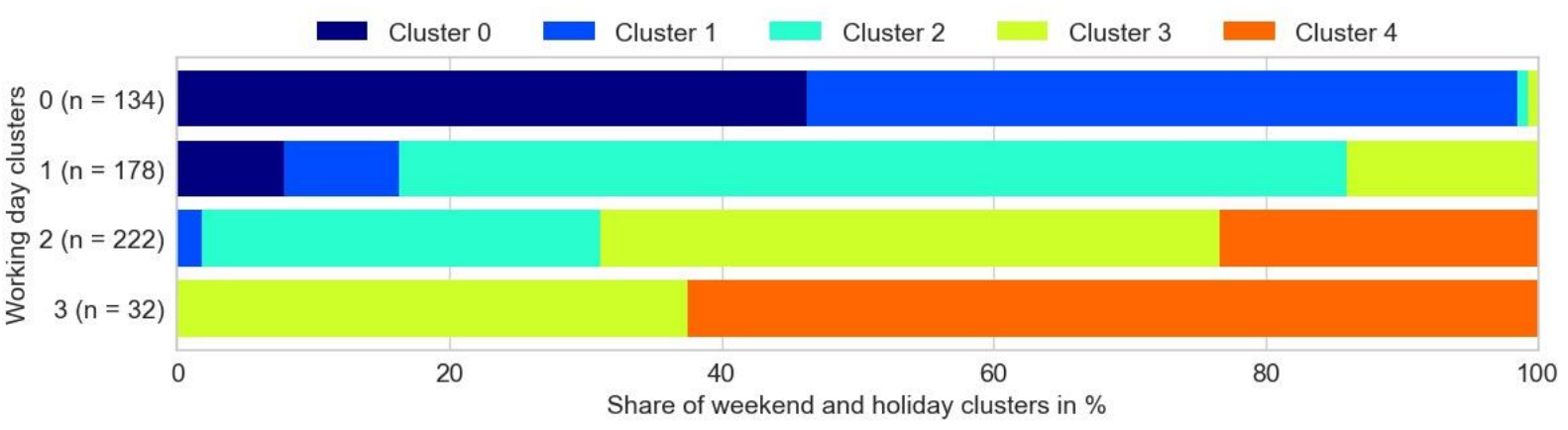

Figure 8: Link of wd- and wknd-clusters.

Figure 9, Figure 10 and Figure 11 visualize the created reference load profiles with a daily resolution at the three defined representative locations. Since the hourly variability of the heat demand can be buffered by a storage tank in most cases, it is neglected for simplification reasons. If an hourly resolution is required, for example in simulation, the daily heat demand can be evenly distributed over all hours of the day. 


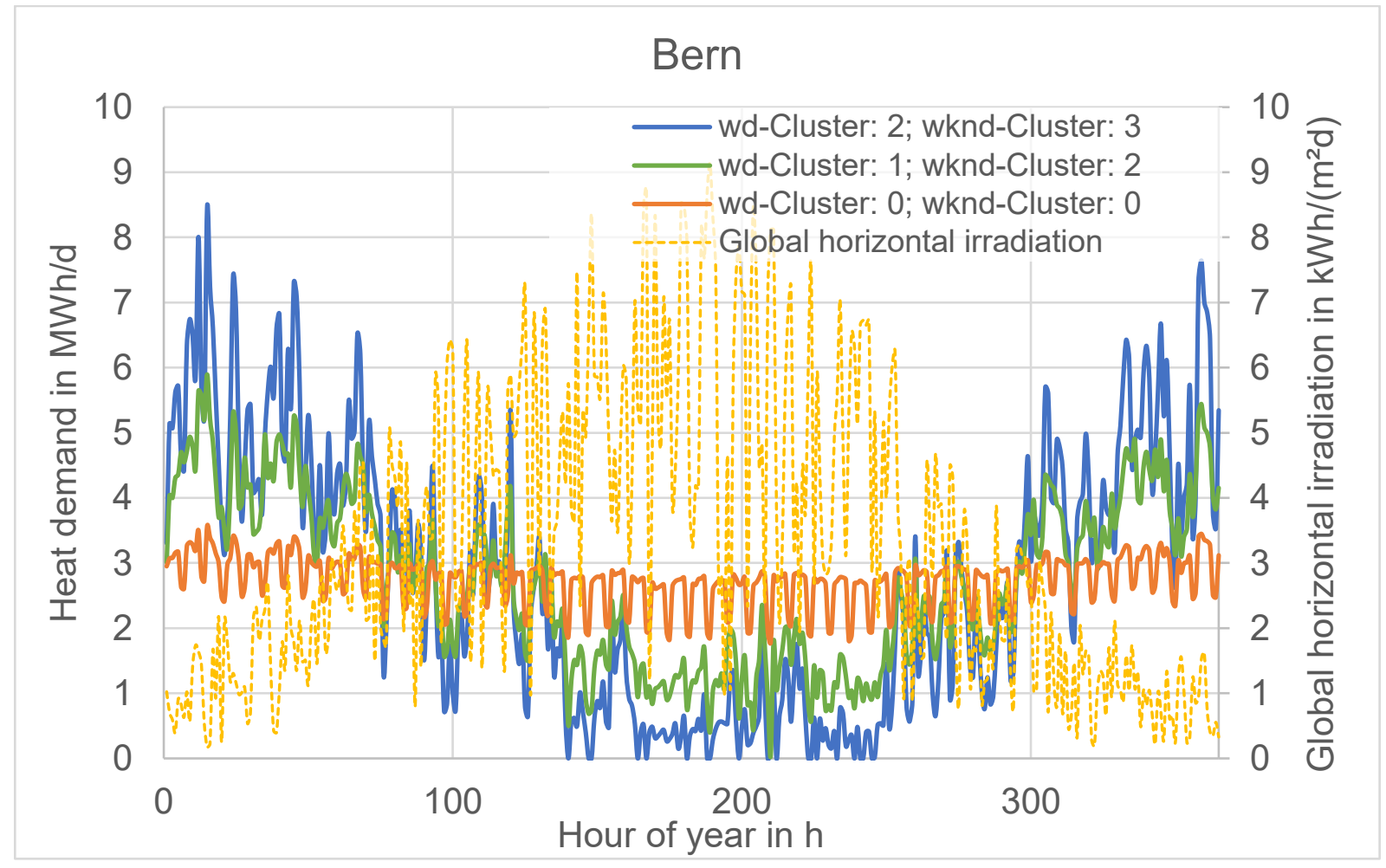

Figure 9: Reference load profiles for location Bern (heat sink temperatures $80^{\circ} \mathrm{C}$ and $150{ }^{\circ} \mathrm{C}$ )

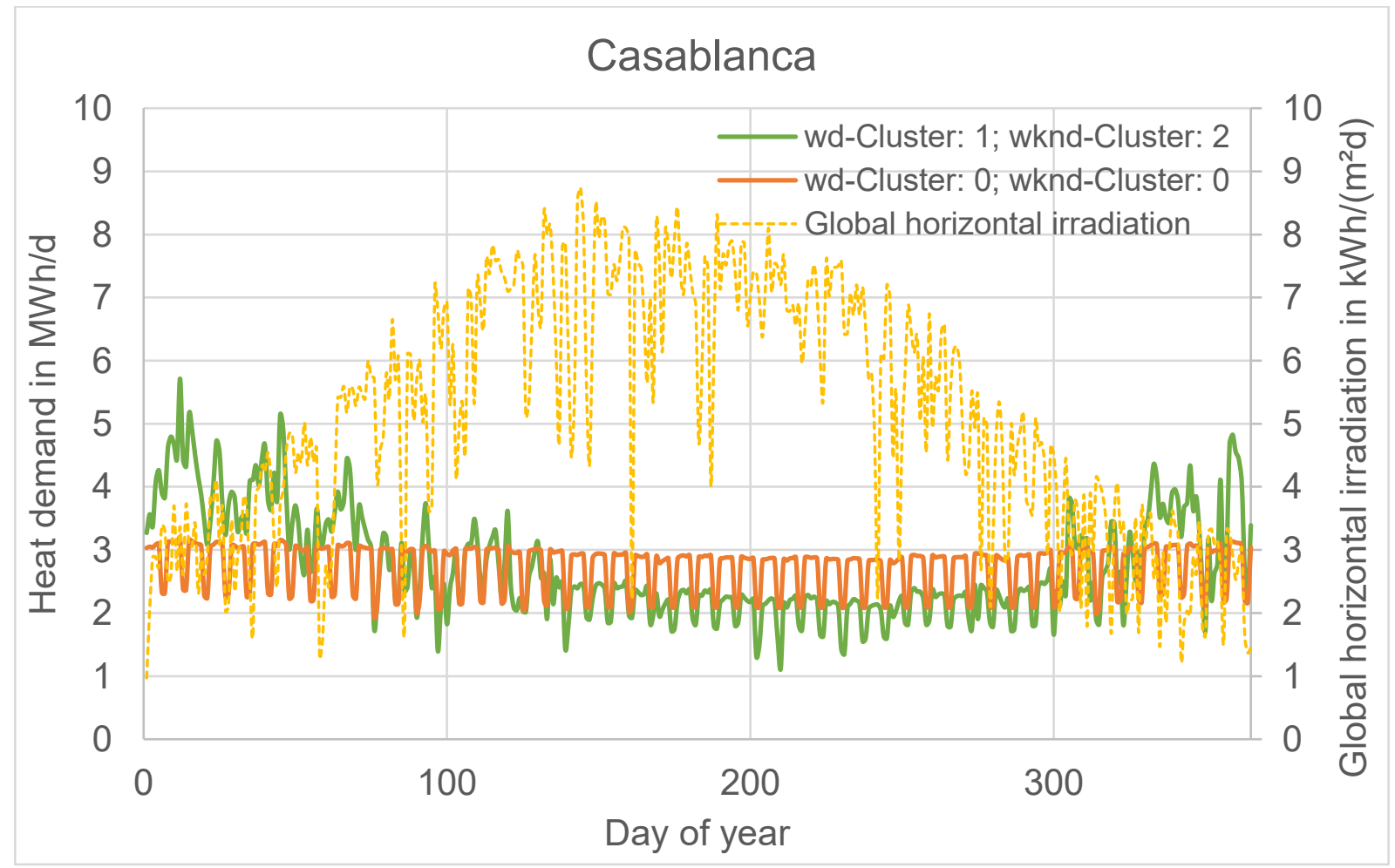

Figure 10: Reference load profiles for location Casablanca (heat sink temperatures $80{ }^{\circ} \mathrm{C}$ and $150{ }^{\circ} \mathrm{C}$ ) 


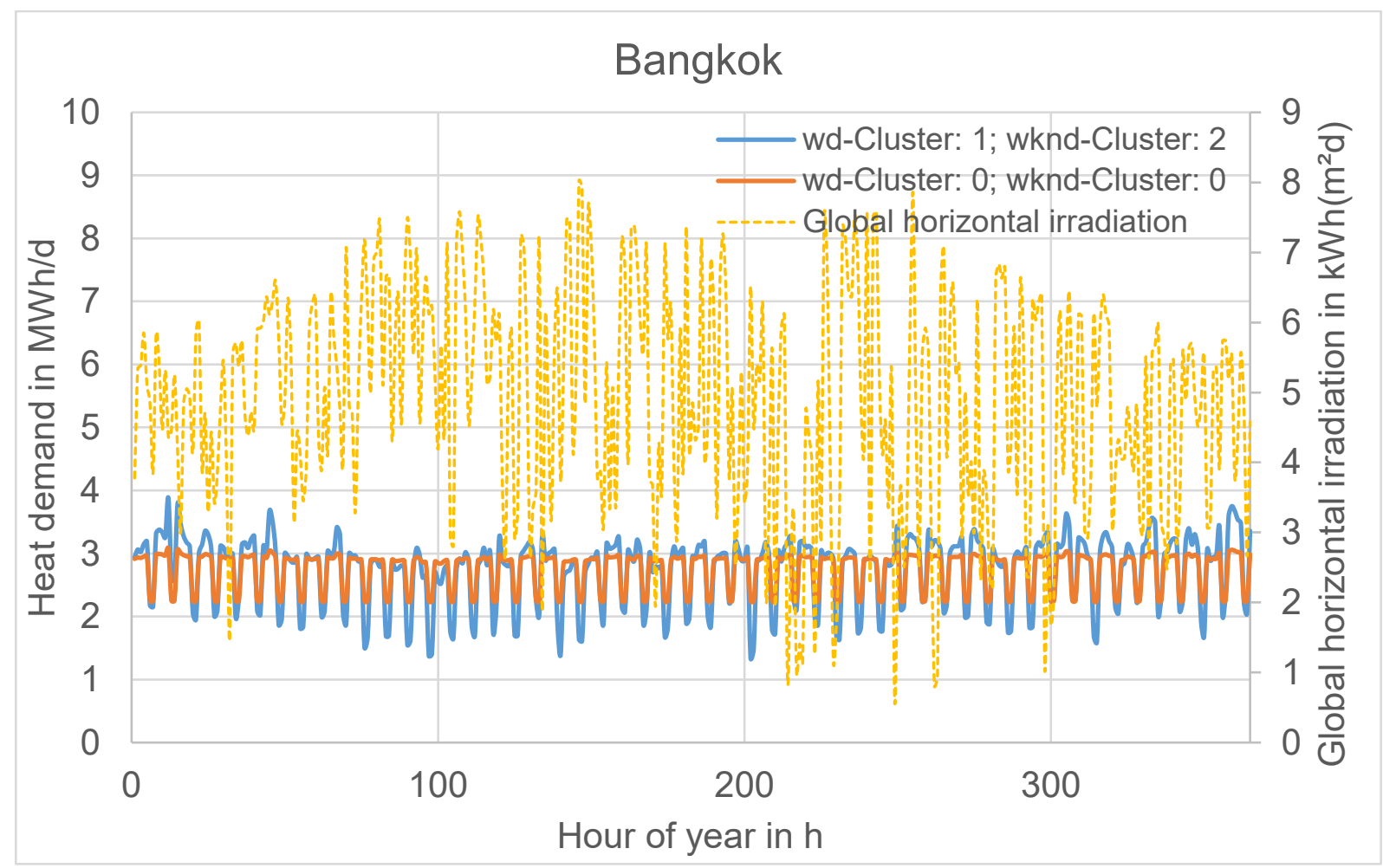

Figure 11: Reference load profiles for location Bangkok (heat sink temperatures $80{ }^{\circ} \mathrm{C}$ and $150{ }^{\circ} \mathrm{C}$ )

\section{Excel Tool}

To easily apply the results of the cluster and regression analysis of 797 natural gas load profiles, an Excel tool was created that can be downloaded at the Task 64 Website (https://task64.iea-shc.org/). This tool creates a generic load profile for a given application based on the methodology described in section 2.4. To adapt to a specific application, the user must select a wd and a wknd cluster. For this purpose, Figure 3 and Figure 4 can be used for orientation Furthermore, the user should select the clusters answering the following questions:

- Which heat sinks are responsible for the largest part of the heat demand?

- Does the heat demand of these heat sinks depend on the ambient temperature?

- Do the selected wd and wknd clusters match the heat sink characteristics in terms of dependency on ambient temperature?

- $\quad$ Do the selected wd and wknd clusters logically match? (It is unlikely that an application will have a fundamentally different characteristic in its dependence on ambient temperature on weekdays than on weekends.

In addition to selecting the clusters, the user must enter a daily ambient temperature profile and the respective year. For all Saturdays and Sundays in the entered year, the wknd regressions are used and for all other days, the $w d$ regressions are used to calculate the normalized daily heat demand. If the user additionally enters the sum of annual heat demand, the tool also calculates the absolute load profile.

\section{Conclusion and Outlook}

Based on the analysis of 797 natural gas consumption load profiles, seven generic reference profiles for industrial heat demand are generated. The profiles reproduce normalized industrial heat demand at three different locations. Seasonal variations of the ambient temperature and of typical heat loads are taken into account. Other influences such as user behaviour and variations of production output were not evaluated and included. To introduce more statistical variations into the profile, randomized variations could be included. 
Within the further progress of Subtask A of IEA-SHC Task 64, these reference normalized heat load profiles will be used to demonstrate the potential and the performance but also the limitations of solar process heat as one technology in renewable heating systems in combination with other renewable heating technologies.

\section{References}

[1] Pag F, Gebele M, Vajen K, Schmitt B. On the importance of ambient temperature dependent process heat and the possibilities of covering it with solar thermal energy. In: Conexio, editor. Proceedings of Solarthermal Symposium; 2018 (in German).

[2] Schmitt B. Integration of solar thermal systems for the supply of process heat in industry. Department of Mechanical Engineering, Dissertation, 2014. Aachen: Shaker; 2014 (in German).

[3] Jesper M, Schlosser F, Pag F, Walmsley TG, Schmitt B, Vajen K. Large-scale heat pumps: Uptake and performance modelling of market-available devices. Renewable and Sustainable Energy Reviews 2021;137:110646. https://doi.org/10.1016/j.rser.2020.110646 